\title{
Editorial
}

\section{Economic Incentives in the Health Care Industry: Implications for Health Policy Making}

\author{
W. Nonneman and E. Van Doorslaer \\ Department of Economics, University of Antwerp, Antwerp, Belgium
}

Accepted 11 November 1986

On 12 and 13 September 1985, the University of Antwerp held its third international conference on 'Health and Economics'. The organizing committee had chosen the economic incentive structure operating in health care as the central theme and invited a number of distinguished speakers from several countries to address this topic from different points of view. The main purpose was to examine the experiences abroad in order to derive conclusions for Belgian health care policy. In spite of the large diversity of health care systems and incentive structures in the various countries, some consensus did emerge on how actual outcomes in terms of efficiency and equity could be brought nearer to the desired outcomes. But before we try to formulate the most important implications for health policy makers, we will first give an overview of the papers that were presented. They are all published elsewhere in this issue.

\section{In search of an optimal incentive structure}

The general theme of the conference was subdivided into four sessions containing three contributions each. The first session was devoted to the incentives in different health care systems in general, while the other three sessions concentrated on the incentives faced by each of the different parties involved in the health care market: providers (both physicians and hospital managers), consumers, and insurers.

Evans reports on the North American post-war experience by contrasting the performance of Canada and the United States in containing health care costs. His

Address for correspondence: Prof. W. Nonneman, Ph.D., Department of Economics, University of Antwerp, Prinsstraat 13, Antwerpen 2000, Belgium. 
main message is that universal comprehensive coverage through public insurance, while preserving private provision on a fee-for-service basis, is capable of controlling costs, apparently without affecting health outcomes. The puzzling thing about 'the world's most successful system for cost restraint' seems to be, at least to us Europeans, why the Canadian provincial governments are doing such a good job in using their monopoly purchasing power over providers. As such, they seem to act fairly effectively as a collective agency for consumers/citizens' interests. European experiences with similar public agencies attempting to exercise a countervailing power have not always been so successful. According to Evans, the answer to this problem is to be sought in a political theory of incentives facing groups of people rather than in the application of standard neoclassical economic theory to the behavior of individuals with respect to health care.

This political market for health policy is precisely the focus of attention in Rutten's contribution. His picture of governmental health care intervention in some Western European countries is quite gloomy. By means of examples taken from different countries with public insurance but private provision of health care, he argues that it should not be taken for granted that collective decision making is in the interest of the consumer/citizen. In order to bring the incentives for the public insurance agencies more in line with the interests of their insured, Rutten advocates the introduction of more competitive elements between these agencies. That the issue of economic incentives cannot even be neglected in public provision systems like the Eastern European national health services is illustrated clearly by Wlodarczyk in his description of the recent developments of the Polish NHS. Recognition of this fact has led to rationalization reforms that include such features as motivational bonuses, free choice of physician, and patient co-payments. Thus far, however, the incentives seem to have had more to do with productivity rather than efficiency, and the experiments are too recent for comprehensive evaluation of their effects.

The second session of the conference was devoted to incentives for cost-effective physician behavior. Freund presents us the results of some alternative payment arrangements which have been implemented in the United States public health care program Medicaid. The new strategy centers around the concept of 'managed care', which implies that the primary care physician becomes a 'case manager' who. to a certain extent, shares the financial risk of his patients' utilization. The preliminary results indicate that the success of case management in terms of cost containment is critically dependent on a remuneration system based on a degree of comprehensive capitation payment, which also includes specialty and hospital care. Both in the non-competitive situation, when county health authorities establish contracts with local practitioners, and in the competitive context, where privately organized primary care networks negotiate Medicaid capitation payments with the state, the financial risk-sharing feature is essential in order to alter service delivery patterns, but it does not seem to be enough. Adequate monitoring of utilization and expenditures also requires well developed management information systems. According to the preliminary evidence reported by Freund, the effectiveness of the case management concept depends not only on the re-arrangement of the financial 
incentives to the physicians but also on the provision of diagnostic and cost information on which they have to base their decisions.

The Dutch experience with hospital budgeting, implemented in 1983, provides another interesting case study. Groot describes the impact of the closed-end financing structure imposed by the government on the behavior of clinicians working in general hospitals. Obviously, it has increased the need for extensive cost information per service delivered, for a re-organization of medical departments into a more hierarchical structure, and for the introduction of peer review mechanisms. However, the tensions created by leaving the salaries of the specialists out ot the budget formula remains a significant problem that may be an obstacle to the emergence of more cost-effective practice patterns in the near future.

In the third contribution to this session, Maynard explores the physician incentive systems operating in the English National Health Service. He argues that, although cost control is not the major problem in a state health care system, the micro-incentive structure is poor, often even perverse, and therefore causes inefficient use of resources. Future reforms are advocated that are based on two features: budgets for practitioners and provider competition for consumers. The budgetholder could be the primary care provider, comparable to Freund's case managers, or the District Health Authority contracting with competing public and private providers. However, it seems unlikely that this type of radical change in the NHS will be considered in the near future by the Thatcher Government, despite all the plans for reform.

The third session was explicitly concerned with incentives for cost-effective behavior in hospitals, as they are being experimented with in the U.S.A., the U.K., and Belgium. The overview given by Neuhauser of recent changes in the U.S. in monetary and non-monetary incentives operating at all levels of the health care delivery system leads to a number of conclusions, that were also put forward by other speakers. For instance, economic incentives alone will not by themselves increase hospital team efficiency. Management skills and appropriate information are necessary complements of such incentives. The introduction of the DRG hospital payment system for Medicare patients seems to be one example of reversal of incentives that have produced dramatic changes in hospital costs and utilization. The use of diagnosis-related groups is also advocated by Wickings but for a different reason. In his view, global and clinical budgets are becoming effective means of cost control in the U.K. but do not address outcomes adequately. DRGs could be used as a tool for associating costs with outcome and quality measures. If constructed carefully, the categorization could give health system managers information about which prices for treatments can be reduced without affecting quality standards but can also provide a warning when lower prices begin to be associated with worsening outcomes.

The recent changes in the rules and incentives for Belgian hospitals are described by Marchand. As of 1986, the retrospective cost-based reimbursement has been changed into a prospective per diem rate payment based on inter-hospital cost comparisons. Although the enactment of this change looks promising because revenue and costs are disconnected, there are still shortcomings. Hospital managers 
still have great difficulties in transferring the pressure on resources to the cost-generating medical practitioners whose medical fees are not subject to the same rate setting procedure. Moreover, multiplication of diagnostic and other procedures may be done in an attempt to compensate for the loss in hospitalization revenue. Several elements of the rate setting process itself, like the separation of cost items, the computation of a 'reference' cost, and the revision of day quotas, need further development in order to prevent undesirable distortions towards inefficient resource allocations.

In the final session the focus was on how the economic incentives to consumers and health insurance agencies could be improved. In his survey of the major developments after what he calls the 'Open-Ended Era', Enthoven explains how the 'Market Competition Era' has emerged in the United States health care economy. In his view, the fast growth of several types of Competitive Medical Plans will continue in the near future and eventually result in a medical care system based only on these types of comprehensive health care financing and delivery organizations. In order to remedy the remaining problems of unfair competition and risk selection, some regulation is advocated along the lines as proposed earlier in his Consumer Choice Health Plan. Otherwise, the radical increase in efficiency could aggravate equity problems.

The ideas of Enthoven and others on regulated competition between providerinsurer organizations led van de Ven to develop a similar proposal for a National Health Insurance Act for The Netherlands. Convergence of public and private insurance agencies towards a uniform health insurance system is suggested as a shortterm strategy. Gradually, both types of insurers should develop into competing organizations like the American CMPs. Although preconditions for system change seem favorable in The Netherlands, it is unclear whether pro-competitive regulatory changes are more likely than the continuation of increased government planning and regulation of health care.

Finally, Zweifel examines the micro-economic effects of bonus systems, a type of consumer incentive that is not frequently used in health care. Although rebates for no claims can be considered as positive rather than negative economic incentives for consumers and may therefore be preferable to more traditional forms of cost-sharing, they have been shown to similarly restrain the demand for medical care much more among lower than among higher income groups. The notion of bonuses is certainly innovative in health care, but its importance should not be overestimated in view of the fairly general consensus that seems to emerge from the other papers presented at the conference that incentives for providers and insurers are more cost-effective than incentives for consumers.

\section{Lessons for Belgium}

What have we learned now from all this? What lessons can be drawn for a small country like Belgium with some 10 million people with extensive national health insurance coverage and one of the highest densities of providers, all remunerated 
on a fee-for-service basis? During the last decade, one of the most popular costcontainment strategies used in this country was the introduction of small co-payments for patients. Now if one thing has become clear from this conference, it is that economic incentives should not primarily be directed at fairly ignorant consumers. Rather, there seems to be a growing consensus for the viewpoint that the focus should be on incentives for providers and insurers. In all the incentive schemes discussed at this symposium be it case management, clinical budgets with or without DRGs, competitive medical plans, or prospective rate setting, the agency role of both providers and financial intermediaries (insurers or health authorities) is reinforced by putting them financially at risk and making them accountable for their decisions. If patients enter the picture they do not do so as users of medical care but as non-users or as shoppers for health insurance. This shift in emphasis is important for future research efforts. Very little empirical knowledge is available on provider behavior and even less is known on how the 'middlemen' of this sector, the insurers and bureaucrats, would react to changing incentives.

Putting the general principle of reinforcing the agency role into practice in the Belgian health care setting would require a redefinition of the role of the sickness funds. At present, they are no (longer) active insurers but predominantly payment offices acting as intermediaries between the state social security system, the premium-payers and taxpayers, and the health care providers. Both premiums and fees are established at the national level, which leaves no room for price competition. Deficits are passed on to the national health insurance agency because the sickness funds are not accountable themselves. There seem to be two major ways in which the sickness fund's role could be strenghthened by putting them financially at risk. The regulatory approach would imply that they get fixed budgets from the national social security budget for which they would have to cover their beneficiaries for a prespecified set of risks. But they should at the same time obtain more autonomy in negotiating payment contracts with individual providers. Whether this limited reform is enough to ensure cost-containment through improved efficiency is unclear, but the Canadian experience with the provincial plans certainly suggests that it is feasible.

The regulated-competition approach would require more profound changes in the system. Sickness funds would have to compete for clients with low premiums but would have the freedom to use their countervailing power to contract selectively with providers. In order to prevent preferred-risk selection, certain regulation would be necessary relating to open enrollment, minimum benefit packages, and supply of information. Distributional goals would be pursued through other means than the insurance system, e.g. through a tax and subsidy program. Nobody really knows yet whether such a plan will work because in the U.S. it has only been introduced in part (the competition is there already, the regulation is not) and in The Netherlands, at present, it only works in the mind of its proponents.

Whichever way is chosen, it would always imply a strengthening of the role of the sickness funds from passive executors to active, competitive insurers. It is most likely that this view will be contested, both by the providers who do not like the prospect of dealing with powerful sickness funds, but perhaps also by the sickness 
funds themselves, which do not seem in favor of too much change. Perhaps Milton Friedman's law of bureaucratic inertia explains why: every large bureaucracy, government or private, is convinced that the way it conducts its affairs is the only way that they can be conducted. 